- Conducted an internal communications drive to encourage the flexing of volunteer roles around skills and/or creating roles requiring specialist skills.

Results Funded by the Health Innovation Network (HIN), we recruited six volunteers with training backgrounds to co-produce a training course for local non-hospice volunteers on talking about death, dying and loss. All volunteers reported high satisfaction levels with using their skills in this project. We have recruited 16 people with professional coaching qualifications to coach senior staff in their ongoing development on a voluntary basis. Volunteers are joining staff working groups to provide new perspective.

Conclusions Every successful role and initiative is breathing more confidence in staff to focus their volunteer involvement around assets rather than boundaries.

Limitations to consider:

- Ensuring potential volunteers are not put off by roles that may feel too much like a paid job;

- Ensuring that skills are welcomed whilst being mindful of focusing on organisational need.

Acknowledgments With thanks to the HIN for funding some of this work.

\section{P-94 IGNORE VOLUNTEER CARERS AT YOUR PERIL - YOUNG ADULTS TO RETIRED ADULTS; DEVELOPING SKILLS TO CARE}

Tricia Wilcocks, Sue Marshall. ellenor, Kent, UK

\subsection{6/bmispcare-2019-HUKNC.117}

Background Staff shortages are a reality, training is not keeping pace with increasing demand for care, fuelling skill shortages, increasing agency costs (The Health Foundation, Nuffield Trust \& The King's Fund, 2018) and increasing pressure on existing staff (Triggle, 2019).

Volunteers are an essential but under-utilised support for hospices (Help the Hospices Commission into the Future of Hospice Care, 2012; Together for Short Lives \& Help the Hospices, 2014). In our hospice volunteers recognised they could do more to help, asking to be trained to support clinical staff in a more practical way (Marshall \& Wilcocks, 2018).

Aim Enable a team of Care Volunteers with skills and experiences to work alongside clinical staff across all care settings.

Methods A pilot project to train Care Volunteers in the ward setting was quickly extended to offer Care Volunteers experience to work in the Day Hospice and Community teams. See Table 1 (Training and support provided for care volunteers).

Results

- Demand for Care Volunteers is increasing across the organisation;

- Increased care hours provided;

- Reduced stress levels on clinical staff;

- Reduced agency costs;

- Dementia patients are supported whilst carers attend training or support groups;

- Increased provision of respite care in community;

- Recruitment to Healthcare Assistants roles from Care Volunteers.
Abstract P-94 Table 1 Training and support provided for care volunteers

\begin{tabular}{lc}
\hline Training & Support \\
\hline Induction in statutory and mandatory topics & $\begin{array}{c}\text { Trained Assessors support, advise, } \\
\text { and monitor progress } \\
\text { Weekly tutorials and observations of } \\
\text { competencies }\end{array}$ \\
An overview of palliative care & $\begin{array}{c}\text { Mobile messaging application } \\
\text { enables communication and support } \\
\text { Practical competencies: moving and handling, } \\
\text { personal care, nutrition and hydration, catheter care }\end{array}$ \\
\hline
\end{tabular}

Case studies Community crisis: A patient's wife was the main carer but became acutely ill, needing hospital admission. A Care Volunteer responded immediately, staying with the patient until a respite bed could be found.

Recognising dying: Care Volunteer providing personal care recognised signs of end of life, alerted staff, enabling family to be with the patient as they died.

Conclusion We need to recognise that these Care Volunteers are a viable alternative to overstretched staff, providing added value to end of life care.

\section{Generating Research, Knowledge and Outcomes}

\section{P-95 AN EVALUATION OF THE FIRST FIVE YEARS OF AN ELECTRONIC PALLIATIVE CARE CO-ORDINATION SYSTEM (EPACCS)}

Karen Chumbley, Emma Tempest, Mary Northrop, Tim Clifton, Caroline Vince, Sarah May. St Helena, Colchester, UK

\subsection{6/bmjspcare-2019-HUKNC.118}

Background UK government policy supports advance care planning and recording of patient preferences on EPaCCs (Department of Health, 2008). EPaCCs have been developed across the country but there is no consensus on evaluation (Allsop, Kite, McDermott, Penn et al., 2017) and assessments are urgently required (Petrova, Riley, Abel \& Barclay, 2016; Callender, Riley, Broadhurst, Wiggins et al., 2017).

Aim This evaluation reviews the first five years of EPaCCS in North East Essex, locally called the My Care Choices register (MCCR) including; uptake of the register; the process of register entry before death and preferred place of care choices and outcomes. This is to contribute to the discussion about how EPaCCs should be evaluated and developed.

Method Data was extracted from MCCR from the date of inception in September 2013 to September 2018. Data recorded on the EPaCCS for residents of North East Essex were compared to Office for National Statistics mortality data to calculate what proportion of deaths had a register entry. The mean number of days prior to death that the register entry was created was calculated. Extraction of data included preferred place of care and subsequent achievement. 